Conclusion Patients with advanced COPD and co-morbid anxiety were more likely to have had contact with their GP. Those with co-morbid depression were more likely to have had an inpatient admission. Variables associated with these relationships may include health related quality of life, co-morbidities and exacerbations managed at home. On-going work will validate these conclusions by analysing data collected over an 18 month period. Supportive interventions targeting patients with comorbid anxiety and depression may ameliorate the effects of psychological morbidity and reduce admissions.

\section{P50 PREDICTING READMISSION FOLLOWING EXACERBATION OF COPD USING A NON-CONTACT SENSOR - A PROOF OF CONCEPT STUDY}

${ }^{1} \mathrm{P}$ Minnis, ${ }^{2} \mathrm{R}$ O'Meara, ${ }^{3} \mathrm{H}$ Kane, ${ }^{3} \mathrm{~A}$ Zaffaroni, ${ }^{3} \mathrm{~F} \mathrm{O}^{\prime} \mathrm{Dea},{ }^{3} \mathrm{~B}$ Britton, ${ }^{2} \mathrm{~B}$ Caulfield, ${ }^{1}$ SC Donnelly. 'Department of Medicine, Trinity Centre for Health Sciences, Tallaght Hospital, Dublin, Ireland; ${ }^{2}$ Insight Centre for Data Analytics, UCD, Dublin, Ireland; ${ }^{3}$ ResMed Nexus UCD, Dublin, Ireland

\subsection{6/thoraxjnl-2015-207770.187}

Introduction and objectives Chronic Obstructive Pulmonary Disease (COPD) is the second most common cause of emergency admission to hospital in the UK. Following an exacerbation there is a high risk of recurrence. Early identification and prompt treatment of exacerbations have been shown to reduce risk of hospital admission. ${ }^{1}$ Respiratory rate changes during an episode of exacerbation and may serve as the warning signal of developing exacerbation. We aimed to determine whether a non-contact bedside sensor (SleepMinder TM) recording Nocturnal Respiratory Rate (NRR) could detect exacerbations in patients with COPD following hospital discharge.

Methods Patients were enrolled following a hospital admission for an exacerbation of there underlying COPD. They were followed prospectively for 12 weeks and monitored by SleepMinder TM (Resmed) technology recording NRR. Demographics and clinical details were extracted from medical records. A research nurse contacted each participant weekly and recorded CAT scores and any healthcare contacts.

Results 15 patients completed the study period and recorded $>75 \%$ of study data. Of these 8 patients had further exacerbations. Median time post discharge for an exacerbation was 56.5 days (IQR 41-67). There were no differences in baseline demographics between those who had an exacerbation and those that did not however there was a trend towards increased BMI, baseline CAT score and length of stay. Of the 8 patients who had an exacerbation a clear signal in NRR could be identified, by visual inspection, in $5(62.5 \%)$ around the time of recorded health care contact. The average time from a signal to health care contact was 6.6 days indicating a window of opportunity for intervention. The was no significant trend between change of CAT score and change of NRR indicating patients may be unaware of impending exacerbation ( $\mathrm{p}$ value 0.243 ).

Conclusions SleepMinder TM technology assessing nocturnal respiratory rate may have use in a real time clinician led connected health setting to trigger early intervention and prevent readmission following discharge.

\section{REFERENCE}

1 Wilkinson TM, Donaldson GC, Hurst JR, et al. Early therapy improves outcomes of exacerbations of chronic obstructive pulmonary disease. Am J Respir Crit Care Med. 2004;169:1298-303
P51

ADVANCING QUALITY (AQ) REDUCING VARIATION AND IMPROVING QUALITY AND OUTCOMES FOR PATIENTS WITH CHRONIC OBSTRUCTIVE PULMONARY DISEASE (COPD) IN THE NORTH WEST OF ENGLAND

1J Roberts, ${ }^{2} \mathrm{D}$ Szwandt, ${ }^{2} \mathrm{~S}$ Hammond. 'Salford Royal Foundation Trust, Salford, Manchester; ${ }^{2}$ AQuA, Sale, Manchester

\subsection{6/thoraxjnl-2015-207770.188}

Introduction and objectives COPD patients in the North West of England die 15 years earlier than expected.

Advancing Quality is a programme of work where a common approach supports quality improvement that focuses on clinical pathways.

Methods A regional clinical expert group agreed the AQ COPD evidence based measures (clinical interventions) in February 2013.

The AQ COPD clinical interventions are:

Within 4 Hours Hospital Arrival: Oxygen - Bronchodilator Corticosteroid - Antibiotic Therapy.

During Hospital Admission: Smoking Cessation - Pulmonary Rehab - Inhaler Technique - Written Self-Management Plan - Spirometry - Home Oxygen - Appropriate End of Life Care - follow up.

Following an initial pilot, AQ COPD went live in September 2014. AQ is a proven approach to improve quality, providing standardisation and transparency for providers and commissioners.

Results Trusts aim to deliver all the interventions that the patient is eligible for, this is known as the Appropriate Care score (ACS). More patients are receiving "perfect care" with AQ, (see Figure 1).

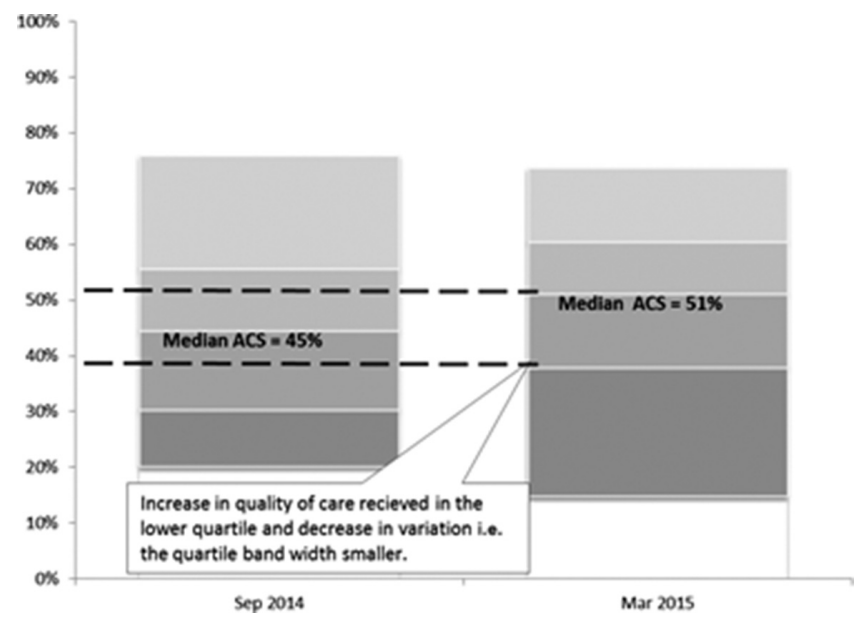

Abstract P51 Figure 1 Advancing Quality (AQ) reducing variation and improving quality and outcomes for patients with Chronic Obstructive Pulmonary Disease (COPD) in the North West of England

Trusts participating in AQ had a mean LOS of 4.7 days compared to 5.7 days for non-participating trusts and average bed days for patients re-admitted in participating trust was 5.5 days compared to 11.8 days in non- participating trusts. Trusts participating saw their readmission rate fall to $20.1 \%$ over the period (a reduction of 9\%).

Conclusion A regional standardised approach, focused on a small but significant set of clinical interventions, can have a significant impact on improving patient care and outcomes. 
In 2015/16 North West CCGs have commissioned AQ COPD across 15 of the 21 Acute Trusts. An AQ incentive framework was also developed for providers and commissioners that supports "doing the right thing" collaborative events ensure that ongoing sharing of best practise happens and we have future plans to expand into Primary and Community Care.

\section{Occupational lung disease}

\section{P52 EPIDEMIOLOGY OF OCCUPATIONAL EXTRINSIC ALLERGIC ALVEOLITIS REPORTED TO SWORD 1996-2014}

${ }^{1} \mathrm{CM}$ Barber, ${ }^{2} \mathrm{M}$ Carder, ${ }^{2} \mathrm{R}$ Agius. ${ }^{1}$ Centre for Workplace Health, Buxton, UK; ${ }^{2}$ Centre for Occupational \& Environmental Health, Manchester, UK

\subsection{6/thoraxjnl-2015-207770.189}

Introduction Worldwide, the true epidemiology of occupational EAA is poorly understood. Data from national reporting schemes offers one method of examining the changing demographics of this disease, and comparing the most commonly reported causes. Methods Data was obtained for all cases of occupational EAA reported to the UK Surveillance of Work-related and Occupational Respiratory Disease (SWORD) scheme since 1996. The likely causative agents for each reported case were grouped into categories, and data compared for the earliest and latest available 5-year time periods (1996-2000 and 2010-2014). An estimate of the annual incidence of occupational EAA was calculated from the estimated number of cases in each time period divided by the average UK working population at that time (data from the Office for National Statistics).

Results Data for the early and late 5 -year time periods are presented in Table 1. The estimated incidence of occupational EAA was similar for the two time periods, but there has been a notable change in reported causation. Occupational EAA due to metalworking fluid, coolant or oil mist exposure has become the most commonly reported cause, responsible for almost a third of all cases. Over the same time period, EAA in mushroom workers has fallen from the joint commonest cause to no reported cases at all.

\begin{tabular}{|c|c|c|}
\hline & $1996-2000$ & 2010-2014 \\
\hline Reported cases & 45 & 39 \\
\hline Mean age & 54 & 54 \\
\hline Gender male:female & $2.7: 1$ & $3.3: 1$ \\
\hline \multicolumn{3}{|l|}{ Reported cause (\%): } \\
\hline Air con/humidifiers & 2 & 0 \\
\hline Avian proteins & 11 & 15 \\
\hline Cleaning agents & 9 & 0 \\
\hline Farming/hay/straw & 22 & 15 \\
\hline Isocyanates & 5 & 8 \\
\hline Mushrooms (edible) & 22 & 0 \\
\hline MWF/coolant/oil mist & 2 & 33 \\
\hline Other cause & 16 & 11 \\
\hline Other mould/fungus & 4 & 13 \\
\hline Unknown & 7 & 5 \\
\hline
\end{tabular}

Discussion The estimated annual incidence of occupational EAA in the UK has remained relatively stable at approximately 1-2 cases per million workers. Although this is likely to represent an underestimate, it is similar to the estimated incidence from reporting schemes in Australia, Catalonia, and the Czech Republic, but an order of magnitude lower than that reported in Finland. Over the last 20 years, EAA due to metalworking fluid exposure has emerged as the most commonly reported cause in the UK. This change has not been noted in other published reporting schemes, where EAA due to agricultural exposures remains the most common aetiology.

\section{P53 DETERMINATION OF SPECIFIC IGE ANTIBODIES TO MOUSE PROTEINS IN LABORATORY ANIMAL WORKERS}

1J Canizales, ' I Welch, ${ }^{1} B$ Fitzgerald, ${ }^{2} Z$ Lightfoot, ${ }^{2} W$ Banya, ${ }^{1} \mathrm{~J}$ Feary, ${ }^{1} \mathrm{P}$ Cullinan, ${ }^{1}$ M Jones. I'mperial College, London, UK; ${ }^{2}$ Royal Brompton Hospital, London, UK

\subsection{6/thoraxjnl-2015-207770.190}

Introduction Laboratory animal workers are at increased risk of developing specific $\operatorname{IgE}$ antibodies to laboratory animal proteins. The major allergen for mouse is Mus $\mathrm{m} 1$ which is predominantly found in the urine. Specific IgE to mouse is determined using either a commercial skin prick test solution of mouse epithelium or ImmunoCAP for either mouse urine or epithelium. Specific IgE to Mus $\mathrm{m} 1$ is used for routine diagnostic testing.

The aim of this study was to compare sensitisation using both ImmunoCAP and skin prick test as well as compare mouse urine and epithelium as allergens. At present there is no gold standard for sensitisation to mouse allergens.

Methods Laboratory workers exposed to mice were recruited to the SPIRAL (Safe Practice in Reduction of Allergy in Laboratories) study. Sensitisation was determined by the presence of specific IgE to Mus $\mathrm{m} 1$ and mouse epithelium using ImmunoCAP (Phadia) (positive result $\geq 0.35 \mathrm{kU} / \mathrm{l}$ ) and by skin prick test to mouse epithelium (positive result is a saline adjusted mean wheal diameter of $\geq 3 \mathrm{~mm}$ ).

Results Of the participants (321), 11 (3\%) were positive by skin prick test, 34(11\%) with specific IgE to Mus m 1 and 35 (11\%) with a positive specific IgE to mouse epithelium.

There were 25/321(8\%) participants with a discordant results between SPT and specific IgE to Mus $m 1$ (Table 1). There were 14 participants with a discordant result between specific IgE to Mus $\mathrm{m} 1$ and mouse epithelium (Table 1).

\begin{tabular}{llll}
$\begin{array}{l}\text { Abstract P53 Table 1 } \\
\text { epithelium in laboratory }\end{array}$ & $\begin{array}{l}\text { Specific IgE to Mus m } 1 \text { and mouse } \\
\text { animal workers }\end{array}$ & & \\
\hline & $\begin{array}{l}\text { Mus m 1 specific } \\
\text { IgE positive }\end{array}$ & $\begin{array}{l}\text { Mus m 1 specific } \\
\text { IgE negative }\end{array}$ & Total \\
\hline SPT positive & 10 & 1 & 11 \\
SPT negative & 24 & 286 & 310 \\
Total & 34 & 289 & 321 \\
Mouse epithelium specific & 26 & 9 & 35 \\
IgE positive & & 286 & 291 \\
Mouse epithelium specific & 5 & & 326 \\
IgE negative & 31 & 295 & \\
Total & & &
\end{tabular}

